\title{
Acqusition and extinction as a function of controlled interval (discrete-trial) or controlled session (free-response) programming ${ }^{1}$
}

JIM MCLEAN AND MELVIN H. MARX UNIVERSITY OF MISSOURI, COLUMBIA

Laboratory rats were trained on either a discrete-trial or a free-responding program of bar presentation, with number of barpresses controlled. Half of the Ss received 16\% sucrose in water as reinforcement, half $64 \%$. The most important result was that Ss which had the discrete-trial type of training produced reliably more responses in extinction, regardless of the extinction program.

This experiment was designed to assess the effect upon extinction performance of a shift in type of bar-presentation program from training to extinction.

The two types of program used were what we have called controlled interval (CI) and controlled session (CS). In the CI program the bar is retracted elther by a press by $S$ or automatically after some set time period, and reappears in either case after a set time period (usually but not necessarily the same as that allowed for presentation). In the CS program the bar remains presented for a set time period regardless of the number of presses and is then retracted automatically for another time period. Each of these programs may be considered operant-box analogues of the discrete-trial procedure typically used in apparatus such as the runway or T-maze, but only recently applied to the barpress situation. The CI program in particular simulates the usual discrete-trial procedure. It seems to generate a very high operant rate and has been used extensively in research in our laboratory.

\section{Method}

The experimental design was a 2 by 2 by 2 factorial with two training conditions (CI $30 / 30$ or CS $30 / 30$ ), two concentrations of sucrose in water, reinforcement ( $16 \%$ or $64 \%$ ), and two extinction conditions (again, CI $30 / 30$ or CS $30 / 30$ ). (In the present notation system the first numeral signifies the maximum duration of bar presentation in sec and the second numeral the intertrial interval). The controlled-operant conditioning apparatus used has been previously described (Marx et al, 1965). The Ss were 64 young female hooded rats bred in our laboratory colony.

The training procedure included the following phases: three days of magazine training (20 trials daily, with .1 ml sucrose reinforcement presented at $30-\mathrm{sec}$ intervals); five days of CI training for all Ss (20 trials dally); and nine days of elther CI $30 / 30$ or CS $30 / 30$ barpress training (20 barpresses per day for each $\mathrm{S}$ ). The extinction test consisted of either 80 trials on CI $30 / 30$ or 20 trials on CS $30 / 30$, all on the same day.

\section{Results}

Figure 1 shows the mean number of extinction barpresses as a function of the type of training program and sucrose concentration. As Fig. 1 indicates, Ss trained on the CI program emitted more extinction responses than those trained on the CS program $(F=12.85$, $d f=1 / 56, p<.01)$, and Ss reinforced with $64 \%$ sucrose emitted more extinction responses than those reinforced with $16 \%$ sucrose $(F=4.63$, df $=1 / 56, p<.05)$. Nelther type of extinction program nor any of the interactions produced reliable differences.

\section{Discussion}

Methodologically, with regard to the most immediate objective of this experiment, the results indicate that the shift from a CI program in training to a CS program in extinction does not contaminate the data obtained from manipulation of other variables. More generally, however, the reliably higher level of ex-

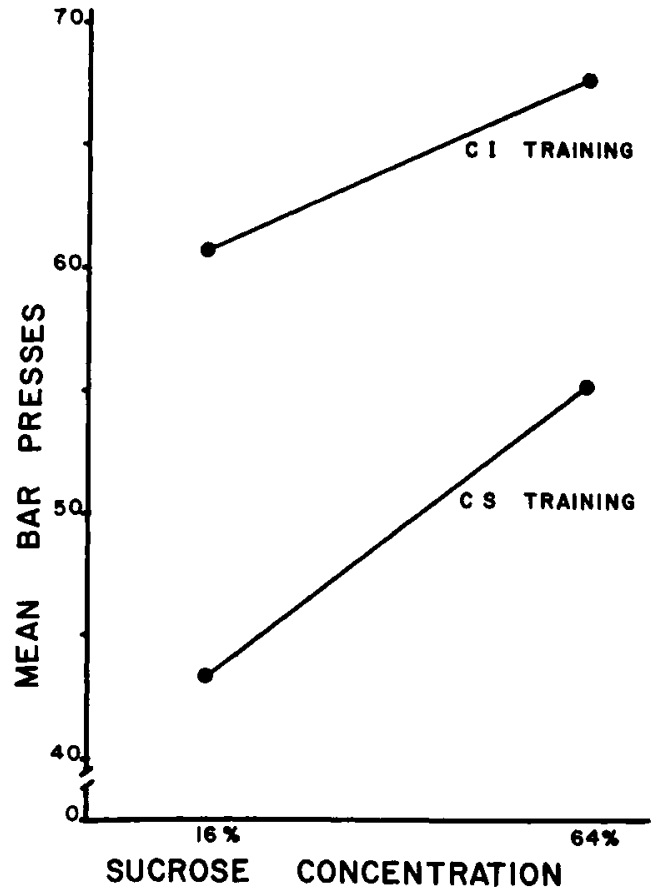

Fig. 1. Mean Number of Barpresses in Extinction for CI and CS Training Programs as a Function of Sucrose Concentration Used for Reinforcement. 
tinction performance shown by the CI-trained Ss demonstrates the ability of this discrete-trial program not only to generate a high rate of operant responding but also to maintain a high degree of operant motivation, at least throughout one day of massed extinction trials. In this respect the CI program appears to act much like the $64 \%$ sucrose concentration, as compared with the $16 \%$ concentration. As a matter of fact, the programming variable was even more powerful in this experiment than the incentive variable, since the CI program at $16 \%$ sucrose concentration reinforcement produced more extinction performance than the CS program at $64 \%$ sucrose concentration reinforcement (cf., Fig. 1).

These results are especially impressive in view of the fact that all Ss initially received CI training, and for several days. It is quite probable that had only CS training been used for the CS group those Ss would have shown even less extinction performance.

The present results thus demonstrate that when a determinate number of reinforced responses is used in training more such responses will be emitted during extinction if reinforcement has been on a discrete-trial rather than a free-responding basis. An important implication of this result is the suggestion that the characteristically high rate of operant response generated by certain reinforcement schedules is not a function of the free-operant procedure per se. This suggestion will be strengthened if the same superiority in response rate can be shown to result from $\mathrm{CI}$ training when it is compared to training on longer CS intervals and intermittent schedules of reinforcement, which more closely approach orthodox free-operant procedures.

\section{Reference}

MARX, M. H., TOMBAUGH, T. N., HATCH, R. S., \& TOMBAUGH, JO W. Controlled operant conditioning boxes with discrete-trial programming for multiple experimental use. Percept. Mot. Skills, $1965,21,247-254$.

Note

1. This research was supported in part by Grant 5853 from the National Science Foundation, Grant HD-00895 from the National Institute of Child Health and Human Development, and by USPHS Research Career Award 1-K6-MH-22, 023 to the second author from the National Institute of Mental Health.

\section{Reply to Baenninger by Stephen R. Goldstein, University of Alberta}

In reviewing some recent research on the behavior of the Siamese fighting fish (Betta splendens), Goldstein (1967) commented upon Baenninger's (1966) interpretation of extinction data reported in an earlier study by Thompson (1963). Baenninger (1967) has now taken issue with my statements by indicating that his position was, in effect, more subtle than my comments implied.

Baenninger's (1967) present view is evidently based upon the assumption that emission rates of an operant may be influenced by changes in the effectiveness of a reinforcer during the course of an experimental session and upon data which show a waning of both the appetitive and consummatory components of aggressive display.

It might be indicated that of the data which support this position, neither Baenninger's (1967) nor Clayton's (cited by Baenninger) were being called into question-though there is room even for this, since the details of Clayton's work have not, to the best of my knowledge, been published, and since in Baenninger's (1966) study, a temperature of $72^{\circ} \mathrm{F}$ was apparently employed in maintaining and testing Ss-a temperature, if we may interpolate from existing data, unfavorable to the initiation and maintenance of aggressive display in Bettasplendens (Lissmann, 1932; Hess, 1952). A temperature of $80^{\circ} \mathrm{F}$ $\pm 2^{\circ} \mathrm{F}$ is recommended by almost all tropical fish texts as ideal for maintaining healthy, active fish and accordingly was used by Thompson (1963) and by myself in replicating his work.

Reference to my paper will indicate, however, that the issue being dealt with was primarily definitional and was not directed at empirical or theo- retical problems. In particular, it appeared that Baenninger (1966) had attributed an extinction-induced response decrement not to the termination of the response-reinforcement contingency, but rather to mirror-image habituation. This point is supported by a statement in Baenninger's (1966) discussion section which read, "It would appear that the reinforcing properties of such stimuli may exist for a limited time only, and that the extinction data reported by Thompson may be due to this decreased tendency to approach mirrors and stimulus fish" (italics mine). It should be apparent, however, that the extinction data in question could not possibly be due to a "decreased tendency to approach mirrors and stimulus fish" since such stimuli are not available to $S$ under conditions that define extinction. Baenninger (1967) has now clarified his position on this by suggesting that habituation may occur under conditions of acquisition and subsequently affect the course of extinction. The confusion could have been avoided had Baenninger distinguished between variables which may affect extinction and the procedural operations which define it.

References

BAENNINGER, R. Waning of aggressive motivation in Betta splendens, Psychon. Sci., 1966, 4, 241-242.

BAENNINGER, R. Reply to Goldstein, Psychon. Sci., 1967, 8, 488. GOLDSTEIN, S. R. Mirror image as a reinforcer in Siamese Fighting Fish: A repetition with additional controls, Psychon. Sci, 1967, 7, 331-332.

HESS, E. H. Temperature as a regulator of the attack response of Betta splendens, Z. Tierpsychol., 1952, 9, 379-382.

LISSMANN, H. W. Die Umwelt des Kampffisches (Betta splendens Regan), Z. vergl. Physiol., 1932, 18, 65-111.

THOMPSON, T. I. Visual reinforcement in Siamese Fighting Fish, Science, 1963, 141, 55-57. 